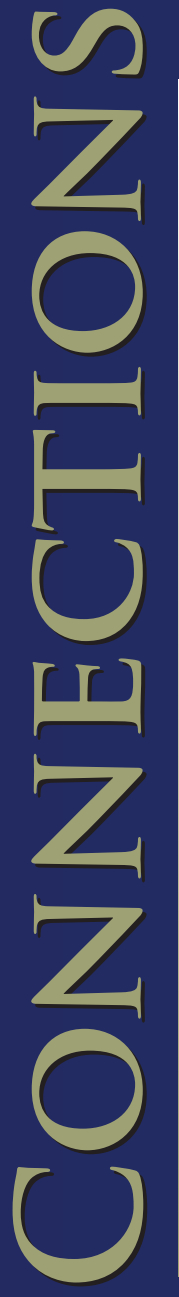

HEAOCTATKИI В СИСТEME ГАОБАМЕОГО УГГРАВАЕНИЯІ ИІ VIX ПIOC $\triangle$ ECTBИЯ MAI OEPABOBAFLGI B CCDEPE OEOPOHDI
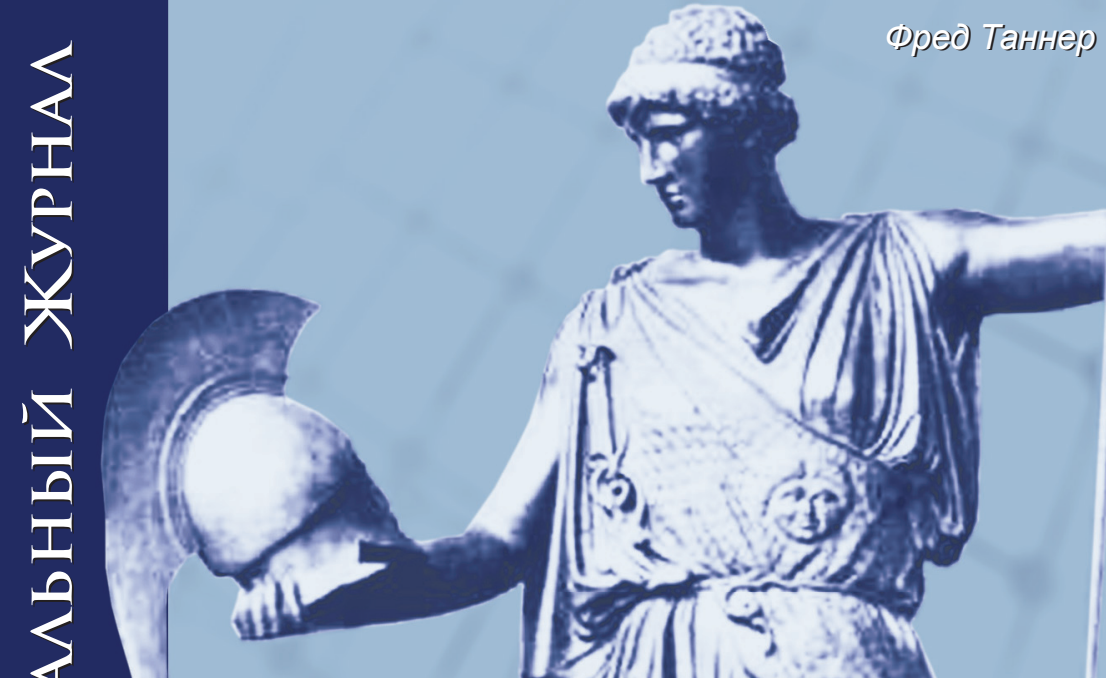

КОНСОРЦИУМ

«ПАРТНЕРСТВО РААИ МИРА»

ВОЕННЫХ АКААЕМИЙ И

ИНСТИТУТОВ ПО

ИЗУЧЕНИЮ ВОПРОСОВ

БЕЗОПАСНОСТИ

ОСЕНЬ 2012
Некоторые ключевые принципы мультинационального военного образования Джеймс С. Корум

Программа совершенствования образования в сфере обороны: клиринговая палата НАТО в области образования в сфере обороны Жан Д’Андурайн и Алан Столберг

Управление стратегическими изменениями через реформы, осуществляемые ПСОСО: перспективы сотрудничества США и Армении по программе «Умная сила» Хайк Котанджян 


\section{CONNECTIONS \\ The Quarterly Journal}

Недостатки в системе глобального управления и их последствия для образования в сфере обороны 1

Фред Таннер

Некоторые ключевые принципы мультинационального военного образования.

Джеймс С. Корум

Программа совершенствования военного образования: перспективы Консорциума ...

\section{Джон Берри}

Образование для реформ: новые учащиеся, новые методы, новые оценки ... Джим Барретт

Преодолевая проблему унаследованных методов обучения 53

Катлийн Райд-Мартинес

Программа совершенствования образования в сфере обороны: клиринговая палата НАТО в области образования в сфере обороны

Жан Д'Андурайн и Алан Столберг

Особые отношения: участие США и НАТО во взаимодействии с инициативой «Партнерство ради мира» в укрепление партнерского потенциала посредством образования. 70

Джеймс М. Кигл

Показывая путь: вклад наиболее новых членов НАТО.

Пьотр Гавличек 
Управление стратегическими изменениями через реформы, осуществляемые ПСОСО: перспективы сотрудничества США и Армении по программе «Умная сила»

Хайк Котанджян

Навстречу Западу: азербайджанский опыт работы по ПСОСО 107

Томас Федисин

Молдавская Военная академия: трансформирование образования офицеров 115 Дюжон Ф. Трокселл

Программа совершенствования образования в сфере обороны: опыт Казахстана

Алан Г. Столберг

Политика и высшее военное образование в Боснии и Герцеговине: упущенные возможности

Хайни Вечера 


\title{
Программа совершенствования военного образования: перспективы Консорциума
}

\author{
Джсн Берри *
}

\section{Ранние годы}

Консорциум «Партнерство ради мира» военных академий и институтов по изучению вопросов безопасности, базированный в Центре им. Джорджа К. Маршалла в Гармише, Германия, осуществляет инновационную и беспрецедентную программу реформирования системы военного образования в пяти странах-партнерах (Армении, Азербайджане, Грузии, Казахстане и Молдовы). Modus operandi (способ действия) программы включает нахождение плодородной почвы для реформ в сфере обороны даже в странах, не являющихся участниками «Партнерства ради мира». Образование в сфере обороны в целом привлекает внимание как полезный инструмент для тех, кто определяет политику. Почему и как это происходит, является интригующей историей, которая просто просится на бумагу. Данная статья является попыткой рассказать эту историю.

Она начинается, как и многие сюжеты времен после Холодной войны, кончиной Организации Варшавского договора и СССР в 1991 году и постоянно растущим интересом стран Центральной и Восточной Европы к членству в НАТО. В то же время, новые независимые суверенные государства, выходцы из СССР, бывшие советские социалистические республики, начали выбирать свой собственный путь. Некоторые из них установили демократические системы управления и связи с Западом, тогда как другие сохранили авторитарных правителей.

Реакция НАТО на все три группы началась как предложение принять протянутую «руку дружбы», как попытка опробовать новую схему отношений сотрудничества. К 1994 году «протянутая рука» переросла в «Партнерство ради мира», практическую программу двухстороннего сотрудничества для тех стран, которые желают участвовать в качестве партнеров вместе с союзниками из НАТО. Сначала НАТО сформировало индивидуальные программы вокруг цели достижения оперативной совместимости в миротворческих операциях, действительно полезной задачи, так как некоторые из партнеров послали свои военные контингенты в Боснию и Герцеговину в 1996 году. К 1999 году НАТО открыло двери для трех новых членов, - политическое решение, основанное главным образом на военных крите-

\footnotetext{
Джон Берри является председателем Рабочей группы по развитию образования (РГРО) Консорциума «Партнерства ради мира». Он начал близко сотрудничать с Консорциумом после того как ушел с должности декана Колледжа обороны НАТО в 2005 году. На этом посту он лично убедился в необходимости помочь странам партнерам, и в частности помочь тем, кто работает в сфере военного образования, освободиться от наследства своих старых систем военного образования путем ассоциирования на профессиональном уровне с их евроатлантическими коллегами. Работа РГРО направлена именно на это.
} 
риях - в частности, на оценке возможного вклада этих стран в военные способности Альянса.

В том же году НАТО одобрило создание Консорциума «Партнерства ради мира», совместной немецко-американской инициативы, учрежденной для укрепления образования и исследований в сфере военного дела и обороны путем международного сотрудничества. Швейцария и Австрия сразу же присоединились к Консорциуму в качестве финансирующих сторон. НАТО осталось на периферии, предпочитая видеть, что организация работает «в духе ПРМ», располагая свободой следовать интересам основателей и членов-партнеров.

\section{Неизведанная территория}

Консорциум пустился в путешествие для исследования неизведанной территории, помогая Партнерам найти свой путь в реформировании сектора обороны и образования в сфере обороны. В эти ранние годы ключевую роль сыграл Швейцарский Центр Демократического Контроля над Вооруженными Силами. Сформировались и начали проводить заседания и обмениваться идеями рабочие группы в областях, затрагивающих интересы как доноров, так и Партнеров. Хотя контакты с западными коллегами были сами по себе ценными, некоторые из рабочих групп стали объектом критики, поскольку не было видно результатов, или «продуктов», как кое-кто говорил, их работы. ${ }^{1}$

В 2004-2005 году перед Консорциумом раскрылась новая дорога после опубликования Плана действий Партнерства по строительству оборонных институтов (ПДП-СОИ) и появления сопутствующей инициативы Образования для реформ в сфере обороны. Вскоре после этого международный секретариат НАТО рассмотрел возможности Консорциума как инструмента влияния на строительство институтов обороны в странах Партнеров и присоединился к Консорциуму в качестве финансирующей стороны. Но какими конкретно задачами должен был заниматься Консорциум? Как и откуда надо было начинать?

\section{Новая энергия, новые направления}

В 2006 году появилась интересная идея. Ad hoc группа профессионалов, работающих в сфере образования в обороне, называющая себя «Друзья ПДП-СОИ», несколько раз организовала встречи в течение года и разработала нечто, что в итоге стало основой действующей сейчас Программы совершенствования образования в сфере обороны, или ПСОСО. Концепция формулы была проста - привлечь западных профессионалов в сфере оборонного образования к дискуссиям между коллегами и их партнерами из стран-партнеров по трем темам:

- Что изучать (т.е. содержание программы)

1 Швейцарская рабочая группа по реформе в секторе обороны, Группа перспективного дистанционного обучения и Австрийская группа по балканским исследованиям были замечательными исключениями. 
- Как преподавать и как учить (педагогика)

- Развитие преподавательского состава (наставничество между коллегами, направленное на целостный подход к образованию в сфере обороны).

Этот рамочной документ стал регламентом для работы одной из первых рабочих групп Консорциума по разработке учебных планов, которая, соответственно, была переименована в Рабочую группу по развитию образования, или РГРО.

В рамках того же времени, в 2007 году, канцелярия министра обороны США, главный источник финансирования Консорциума, призвала организацию представить конкретный план действий в поддержку своей новой политики «Строительства потенциала партнерства». Этот призыв сопровождался неявным предупреждением: будущее финансирование зависит от результатов.

Ничто так не стимулирует творческую активность, как угроза лишиться жизненно важного источника финансирования. И именно так и случилось. Председатель РГРО и исполнительный секретарь Консорциума придумали словосочетание «Программа совершенствования образования в сфере обороны» и наметили первоначальную рамку программы, предлагая в качестве цели «Содействовать профессионализации офицерского корпуса и гражданских должностных лиц в сфере обороны стран-партнеров путем усовершенствования учебных планов и методов учебы, развития преподавательского состава и институций и применения комплексного подхода к профессиональному военному образованию на основе устойчивого взаимодействия».

\section{Начало выполнения ПСОСО}

Каждой ПСОСО руководит старший специалист в области образования в сфере обороны, доброволец, которому компенсируют только его дорожные расходы. ПСОСО должна быть сконфигурирована в соответствии с заявленными потребностями страны-партнера, с начальным временным горизонтом в три года. Ведущую роль в определении общих рамок этих потребностей играет Международный секретариат НАТО посредством Индивидуального плана действий по партнерству (ИПДП) каждой страны-партнера. Гарантированная «сверху-вниз» обязательность ИПДП, официального документа, под которым стоят подписи обеих сторон, означает, что опыт руководителей ПСОСО будет встречен доброжелательно еще с самого первого контакта. Это так же означает, что их партнеры, старшие специалисты в сфере военного образования страны-партнера, имеют данный сверху мандат на реализацию изменений, что немаловажно в странах, незнакомых с изменениями, которые инициируются низовыми звеньями.

Местом для испытания всех этих идей был выбран Казахстан. При сильной поддержке Центрального командования вооруженных сил и канцелярии министра обороны США, Консорциум начал выполнение своей первой ПСОСО с Национальным университетом обороны (НУО) Казахстана в конце 2007 года. Большинство «правил движения» для будущих ПСОСО были разработаны в этом пилотном проекте. Первым шагом был выбор руководителя программы, которым стал док- 
тор Ал Столберг из Военного колледжа Сухопутных войск США. Естественным выбором на должность руководителя ПСОСО его сделали хорошее знание процесса планирования и реализации программ сотрудничества в сфере обороны во многих странах Европы и Евразии как результат его работы в Объединенном штабе и в Европейском командовании вооруженных сил США, и его позиция в преподавательском составе Военного колледжа.

\section{Три чашки чая}

Метафорой, которая сформировала подход к этой первой ПСОСО, стала широко популярная в те годы книга Грега Мортенсона Три чашки чая. Доктор Столберг рассматривал свою первую поездку в Шушинск в конце 2007 года как свою первую чашку чая, возможность встретиться и установить отношения с руководством министерства обороны и с преподавательским составом казахского Национального университета обороны. Появился проект плана действий, доктор Столберг принял на себя руководство в первом мероприятии, лекциях и наставнической сессии по теме преподавания национальной стратегии обороны (вторая чашка чая). Последовали другие мероприятия по темам, которые интересовали казахских преподавателей.

Третья чашка чая, метафорически, появилась с одним из этих ангажементов: предоставления команды преподавателей по методам обучения, которые сконцентрированы на учащихся, как раз полностью противоположными сконцентрированному традиционно на преподавателе обучению, которое преобладало в советской системе. Руководство и академический состав НУО восприняли этот подход и начали экспериментировать с ним. Когда доктор Столберг вернулся в Казахстан для первого ежегодного обзора ПСОСО, через восемнадцать месяцев после его первого визита, преподавательский состав с гордостью заверил его, что они ввели новые методы учебы в значительное количество учебных дисциплин. Доктор Столберг в больших подробностях описывает увлекательное путешествие казахской ПСОСО.

Как стало видно из пилотного примера Казахстана, установление доверия, которое следует из многократного чаепития (т.е. разговоров), может помочь задействовать и стимулировать сдерживаемое желание проведения реформ в странепартнере. ПСОСО показало руководству вооруженных сил и правительства возможный путь реализации реформ, путь, который давал им гибкие возможности делать свой собственный выбор.

Первый успех в Казахстане дал уверенность Консорциуму задействовать другие ПСОСО в 2008 году. На этом этапе НАТО уже играло ключевую роль. Используя неофициально миссии НАТО в Грузии, Азербайджане и Армении и применяя механизм Индивидуального Плана Действий по Партнерству (ИПДП), Международный секретариат НАТО настоятельно призвал эти страны включить образование в сфере обороны в список целей их ИПДП. Быстро один за другим, высшие должностные лица из министерств обороны этих стран попросили высшее должностное лицо НАТО, на уровне помощника генерального секретаря, начать 
диалог о потенциальных реформах в сфере образования. Молдова, без внешнего вмешательства, попросила о собственной ПСОСО в начале 2009 года в письме своего президента к генеральному секретарю НАТО. Казахская ПСОСО распахнула дверь для реализации этих дополнительных программ.

\section{ПСОСО в действии}

\section{Кто делает работу?}

Было бы полезно здесь задаться вопросом, почему квалифицированные западные представители в академических средах вообе задумывались бы об участии в команде ПСОСО. Даже если не учитывать факт, что повсеместно военным на действительной службе не разрешено получать никакой денежной компенсации, кроме своей нормальной зарплаты, зачем вообще тогда добровольно принимать участие? Конечно, ответ на этот вопрос различный для разных людей, но чаще всего находится в списке следующих соображений: возможность для профессионального развития; новые профессиональные вызовы; желание оторваться на время от рутинных задач; возможность попутешествовать и возможность помочь коллегам и их родным странам освободиться от наследия Холодной войны. Несколько отличных специалистов в сфере образования (и важно отметить, не только из США) сами предложили свое время и опыт.

Но тут необходим и еще один ингредиент. Даже если они и волонтеры, даже если их расходы полностью компенсируются Консорциумом и НАТО, а не теми институциями, в которых они работают, то как насчет того, что они определенное время будут отсутствовать на своей обычной работе? Короче, почему их начальство одобряет и разрешает периодические отсутствия своего персонала? К счастью для ПСОСО, военные преподаватели проводят занятия в рамках определенных циклов. Между этими циклами многие преподаватели располагают свободным от занятий временем, и это дает им возможность переезжать. И если время отсутствия от институции своей постоянной работы недолгое, а отсутствие связано с профессиональным развитием, многие руководители поддерживают преподавателей в желании воспользоваться преимуществами таких возможностей. Тщательной подгонкой расписаний, как со стороны волонтеров ПСОСО, так и со стороны стран-партнеров, планы действий ПСОСО двигаются вперед.

Замечательной особенностью ПСОСО является то, что работа делается добровольцами, обеспечивается институциями, основанными на принципе добровольного участия, и одобряется странами на добровольной основе. Хотя США обеспечивают большую часть финансирования и специалистов в сфере военного образования и делают многое при конфигурации содержания ПСОСО, они ни в коем случае не одиноки в этом деле. Вклад НАТО через влияние на ИПДП, общественное признание, которое НАТО обеспечивает как реформам образования в сфере обороны в странах-партнерах, так и поддержке со стороны союзников, его координирующая роль в организации расписания мероприятий и привлечения специалистов по образованию из стран НАТО, и сами эти специалисты, все это в сочета- 
нии позволяет программе успешно развиваться. Также свой вклад дают такие страны как Швейцария, Австрия, Канада, Польша, Венгрия, Чешская республика, Румыния, Литва, Латвия, Эстония и Нидерланды.

\section{Кто платит?}

Для того, чтобы начать осуществление ПСОСО, был нужен еще один шаг. Неизбежный вопрос - Кто будет платить за все это? - требовал ответа. Здесь заслуга принадлежит канцелярии министерства обороны США, которая решила предоставить финансирование из счета, который был создан в середине 1990-х и назывался Фонд «Варшавская Инициатива» (ФВИ). Этот фонд, задуманный в 1994 году и предложенный президентом Клинтоном в его речи в Варшаве, ежегодно накапливал средства в поддержку стран, участвующих в инициативе НАТО «Партнерство ради мира».

В данном случае администрация Консорциума ПРМ успешно использовала свое влияние для того, чтобы получить скромную долю средств со счетов ФВИ, достаточную для оплаты дорожных расходов специалистов по образованию из стран-партнеров, из США, и в некоторых случаях и из стран НАТО на участие в мероприятиях по плану действий ПСОСО. Хотя это всегда нелегко - ввести новый расход в жесткий процесс планирования бюджета, канцелярия министерства обороны признала потенциальный вклад ПСОСО по двум направлениям политики в отношении стран-партнеров: развитие потенциала партнерства и строительство институтов обороны.

В этот критический момент большое значение имел тот факт, что никакие расходы на оплату времени и квалификации участников не были включены. Консорциум просил деньги только на самолетные билеты и на дневные расходы. Весь годовой бюджет ПСОСО и связанных с ней программ (о которых речь пойдет ниже) составлял приблизительно 500000 долларов, которые можно сравнить с ошибками от округления в многомиллиардном военном бюджете США.

Успех привлек новых доноров, и НАТО решительно включилось со своим собственным финансированием, обращая внимание в основном на тех европейских специалистов по образованию, которые решили предоставить свое время и опыт в распоряжение ПСОСО. НАТО так же обеспечивает поездки представителей странпартнеров и иногда даже помогает финансировать командировки очень нужных специалистов из США, которые не были включены в годовой бюджет. Что касается стран-партнеров, то они часто не располагают фондами на финансирование множества этих образовательных инициатив. Однако, почти в каждом случае они проявляют щедрое гостеприимство, обеспечивая проживание и культурную программу.

\section{Примерная программа}

Мероприятия ПСОСО, проводимые в стране-партнере, не являются самыми главными в программе. Два других элемента совершенствования образования в сфере 
обороны имеют существенное значение и напрямую связаны с целями, о которых шла речь выше: чему учить, и как учить и учиться.

Независимые государства стран-партнеров появились после распада СССР, и у них было мало собственных образовательных институций. Содержание курсов, которые им были знакомы, было подчеркнуто советским и прорусским. Консорциум еще в начале проекта ПСОСО понял, что создание умения того, как написать хорошую программу, с целями и задачами, основанными на общепринятых принципах конфигурирования программ, является вопросом, который требует особого внимания. Менторская помощь в конкретных академических дисциплинах и в подборе содержания курсов так же полезны странам-партнерам. Хорошие учебные планы тоже способствуют пониманию целостного характера военного образования, иерархии училищ, которые делают из курсанта полковника.

Путь к решению этих проблем проложила работа в рамках Консорциума Канадской академии обороны (КАО). План НАТО действий Партнерства по строительству оборонных институтов (ПДП-СИО) стал идеальным отправным пунктом. Доктор Дэвид Имелайфонву из КАО возглавил многонациональную команду специалистов по образованию из стран Альянса и стран-партнеров, которая составила проект Примерной программы по Строительству оборонных институтов, первого многонационального совместного действия такого типа, направленного на развитие образования в сфере обороны в странах-партнерах. В этом контексте термин «Примерная программа» имеет специальное значение. Она предлагается странампартнерам не в качестве точного предписания, которое надо принять к выполнению один к одному, а скорее как система основных положений, которые надо иметь в виду при определении содержания своих собственных курсов, основываясь на методах построения учебных планов, которые изложены в документе.

Другая Примерная программа последовала через два года, амбициозное начинание с фокусом на базовое профессиональное образование офицеров. В настоящее время идет выполнение третьего проекта, касающегося профессионального военного образования сержантов, и ожидается, что он будет опубликован в октябре 2013 года. НАТО приняло существенное участие в распространении этих программ, отпечатав и направив их во все миссии НАТО и, как и Консорциум, разместив их на своих вебсайтах.

\section{Педагогика, ориентированная на личность учащуегося}

Третий столб ПСОСО, и возможно наиболее проблематичный, это вечный вопрос «Как учить?». «Как преподавать?», является просто альтернативной формулировкой той же задачи, но специалисты по образованию в общем отдают предпочтение подходу, при котором основное внимание обращается на результаты учащихся, а не на проблемы преподавания. На протяжении веков высшие военные училища делали ставку на пассивное изучение лекций, читаемых уважаемыми старшими офицерами и педагогами. Некоторые из более прогрессивных институций использовали метод вопросов и ответов, но не применяли никакие активные форумы, при которых авторитету преподавательской кафедры может быть брошен вызов. В це- 
лом, таково было состояние вещей, когда специалисты по образованию из США и НАТО начали работать по ПСОСО в странах-партнерах.

Увидев возможность оказать влияние на результаты обучения в странах-партнерах, Консорциум обратился к Военно-морской школе последипломного образования США с просьбой сформировать команду специалистов по педагогике. Затем Консорциум попросил стран-партнеров выбрать своих специалистов в сфере военного образования для участия в трехдневной рабочей встрече, «посвященной изучению и развитию перспективных подходов преподавания и учебы». Консорциум проводит этот семинар каждый год, начиная с 2007 года, и в нем уже участвовали более 150 специалистов по образованию из стран-партнеров.

Под мудрым руководством доктора Катлийн Райд-Мартинес, спектр вопросов этого ежегодного события со временем настолько расширился, что на последнем семинаре, состоявшимся в Армении, цель была «порассуждать вместе о методах учебы, преподавания и оценивания, которые способствуют образовательным инициативам, основанным на лучшем понимании и лучших практиках, нашедших место в опыте всех участников». Сверхзадачей этого мероприятия является создание все увеличивающейся когорты специалистов по образованию в сфере обороны из стран-партнеров, которые имеют желание и способны внести изменения в своих школах и колледжах. Стоит отметить, что сдвиг в сторону моделей, фокусирующихся на личности учащегося происходит и на Западе, где они тоже являются относительно новыми и проблематичными.

\section{Имеет ли все это значение?}

Мой вывод заключается в том, что да, эти программы имеют значение. Партнеры демонстрировали прогресс на каждом ежегодном обзоре состояния и просили продолжать свою ПСОСО и после первоначального трехлетнего срока. В каждой стране были добавлены новые уровни профессионального военного образования. Везде были, или скоро будут учреждены высшие командные и штабные колледжи. Казахстан создал у себя высший военный колледж, а другие страны изучают возможность создания такого. Структура и содержание курсов во все большей степени отражает влияние этого контакта с Западом, который осуществила ПСОСО. Уже применяются новые методы учебы, полностью заменяющие старые лекционные методы, основанные на повторении, семинарах и взаимодействии между учащимися и преподавателями. Пока эти изменения не являются необратимыми и на них оказывают влияние сокращения бюджетов и текучесть кадров. Но они реальны. Понятно, что партнеры сделали большую часть работы сами, но метод «равный-равному», применяемый в ПСОСО, означает, что западные коллеги прошли всю дорогу вместе с ними, помогая, предлагая и давая наставления.

И последнее, программы ПСОСО вызваны к жизни требованиями спроса, а не предложения. Планы действий построены вокруг потребностей, заявленных странами-партнерами, но пользуясь возможностью общаться с западными специалистами по образованию, они могут свободно предлагать новые подходы. Команды ПСОСО возглавляют специалисты в сфере образования, которые жертвуют своим 
временем, а не действующие по приказу офицеры. Институции военного профессионального образования, в которых они работают, одобряют их участие. Дорожные и дневные расходы остаются умеренными и выплачиваются США или НАТО, ничего не стоя странам-партнерам. Консорциум и Международный секретариат НАТО обеспечивают жизненно важную поддержку волонтерам, без чего источник волонтерства быстро бы иссяк. Консорциум работает в близком и плодотворном сотрудничестве с НАТО, где Индивидуальный план действий по партнерству обеспечивает готовность к осуществлению перемен в командном порядке. Не менее близкое и мультиплицирующее сотрудничество осуществляется с канцелярией министерства обороны США. Фонд «Варшавская инициатива» является финансовым сердцем ПСОСО.

Другим показателем успеха является появление инициированной НАТО программы ПСОСО за пределами «Партнерств ради мира». Хотя пока на ранних стадиях планы действий по ПСОСО для Мавритании (страна Средиземноморского диалога) и для Ирака и Афганистана уже приобретают форму. И перспективы будущего весьма обещающие, а все это началось десять лет назад пионерской работой Консорциума ПРМ. 